\title{
Identification of Rainfall Intensity by Using Bahir Dar C-band Weather Radar products
}

\author{
Abebe Kebede Habtegebreal and Abebaw Bizuneh Alemu
}

\begin{abstract}
Observation of rainfall accumulation, distribution and wind direction spatially and temporally is very essential for meteorologists and hydrologists in the Upper Blue Nile basin and different locations of Ethiopia. The Bahir Dar (BAH) Cband weather radar used to estimate the intensity, amount and distribution of precipitation with a high resolution temporally and spatially. It is dual polarization with horizontal and vertical reflectivity; six variables are used to determine the hydrometer and non-hydrometer types, shape and sizes of targets up to range of $250 \mathrm{~km}$ and $450 \mathrm{~km}$ at constant altitude plan position indicator (CAPPI) and plan position indicator (PPI) products. From our first observation, we used different types of products to observe rainfall intensity, distribution, wind direction and warnings across Upper Blue Nile. For RainN on 01 July 2016 the rainfall distribution over twenty four hours $(24 \mathrm{Hr})$ UTC at Bahir Dar, parts of lake Tana, most northern parts, western parts of Gondar town, and south western parts of lake Tana a resolution of $809 \mathrm{~m} /$ Pixel with frequency of $600 \mathrm{~Hz}$ the maximum rainfall accumulation $91.6 \mathrm{~mm}$ was achieved. By using CAPPI product with vertical height of $1 \mathrm{~km}$ on 26 June 2016 the maximum reflectivity $53.5 \mathrm{dBZ}$ is observed.
\end{abstract}

Index Terms-Weather radar, intensity, reflectivity.

\section{INTRODUCTION}

$\mathbf{T}$ $\mathrm{HE}$ C-band dual-polarization weather radar system is one of the most important instruments for observing weather and early warning systems. The washera (BAH) Cband weather radar established in 2016 of Ethiopia more valuable for the Upper Blue Basin of Ethiopia. The dualpolarization radar started by [1], [2] and a valuable improvement was done by [3], [4], [5], [6], [7], [4], [8] improvements, analyze and verify variables available with linearly orthogonal polarimetric radars. The polarimetric radar is implemented for different applications like climate change, hydrological extremes, warnings, short-term forecasts, and quantitatively precipitation estimation [9].

The thermodynamic process of thunderstorm development is used to detect the coverage and intensity of precipitation and basis for severe thunderstorm and tornado warnings issues [10]. The polarimetric weather radar has been functional simultaneous transmission and reception of both horizontally and vertically polarized pulses [11].

The purpose this paper is to provide the first observation Bahir Dar (BAH) weather radar and observation of different output products with different range, azimuth and zenith angle

Manuscript received February 15, 2019; accepted April 27, 2019.

A.K. Habtegebreal is with Department of Physics, Bahir Dar University \& Arba Minch University, Ethiopia. E-mails: abeasella@gmail . com

A.B. Alemu is with the Department of Physics,Bahir Dar University, Ethiopian Institute of Textile \& Fashion Technology, Ethiopia. E-mail: abebawberediffmail.com to see targets of rain, wind and warning products in the future further work for operational meteorologists and hydrologists. Based on standard algorithms and assumptions, various products of practical utility for issuing forecasts and the warning to generate from base parameters; plan position indicator (PPI), range height indicator (RHI), maximum reflective display (MAX), vertical integrated liquid (VIL), base echo, top echo, tracks-250Km, tracks-450Km, RAIN1, RAINN, constant altitude PPI (CAPPI) products and in addition to these some values of non-meteorological targets are detected for the first time observation by using C-band weather Radar at Bahir Dar, Ethiopia.

\section{STUdy AREA}

The Bahir Dar C-band weather radar covers most North western parts, partly south western and central parts of Ethiopia. Most of the Ethiopian landmass is part of the East African Rift Plateau with different elevation above sea level. The topography Horn of Africa increases with height above sea level [12] and reaches highest peak 4,620 meters Ras Dashen mountain north east of Gondar in Ethiopia. The northwestern highlands are considerably more extensive and rugged mountain are divided into northern and southern sections by the valley of the Blue Nile [13].

The rivers of Ethiopia originate in the highlands and flow outward in many directions through deep gorges [14]. The Blue Nile tributaries account for two-thirds of the Nile River flow below Khartoum in Sudan. Because of the general westward slope of the highlands, many large rivers are tributaries of the Nile system, which drains an extensive area of the central portion of the plateau [15]. The Blue Nile, the Tekeze, and the Baro are among them and account for about half of the country's water outflow [16].

In the Ethiopian Plateau, the weather is cool, mild or pleasantly warm, depending on the altitude, with a season characterized by scarce rains [17] from November to February, and a rainy season from June to September, preceded by a period, from March to May, when some showers and thunderstorms occur.

\section{Data And Methodology}

The Bahir Dar (BAH) Weather radar operates in C-band of the electromagnetic spectrum with energy bands corresponds to wavelength 4 to $8 \mathrm{~cm}$. Radar emits a pulse of electromagnetic energy scattered by the atmosphere [18] and some of energy returned to the radar antenna to display a variety of information about the atmosphere indicating the location of 


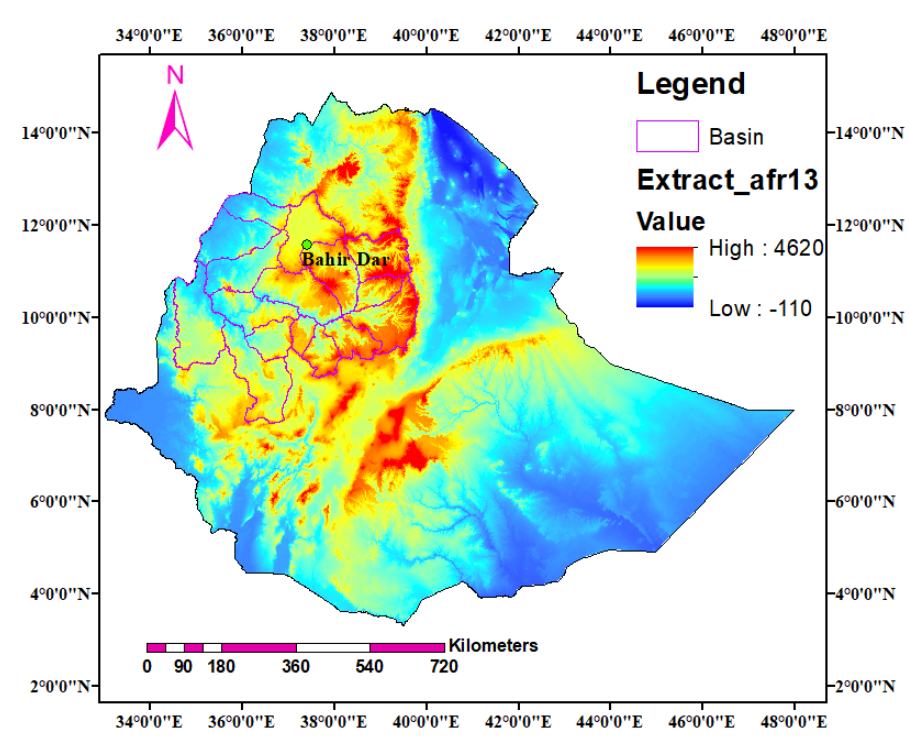

Fig. 1. The location of Bahir Dar Weather Radar and the topography of Ethiopia

precipitation, amount of reflectivity, rainfall accumulation and distribution of rainfall spatially [19].

The BAH C-band weather radar measures moment at both horizontal and vertical polarizations. Groundlevel precipitation estimates from typical radar systems are made for areas of typically $2 \mathrm{~km}^{2}$, successively for 5-10 minute periods using low elevation plan position indicator scans with beam widths of 0.5 degree. In processing the returned energy, it is assumed that all the energy comes from the aimed direction of the beam [1].

The radar reflectivity $(Z)$ and rainfall rate $(R)$ are related, where $\mathrm{Z}$ is proportional to the backscatter power from a radar scan for measuring rainfall [20]. The radar reflectivity (Z) assuming spherical droplets can be expressed as:

$$
\int_{0}^{\infty} N(D) D^{6} d D m m^{6} m^{-3}
$$

where $N(D) d D$ is the number of concentration of droplets with diameter between $D$ and $d D ; Z$ usually measured in $\mathrm{dBZ}$ can be expressed on a logarithmic scale as

$$
Z(d B Z)=10 \log _{10}\left(\frac{Z\left(m m^{6} m^{-3}\right)}{1 m m^{6} m^{-3}}\right)
$$

Empirical relationships exist relating $\mathrm{Z}$ to $\mathrm{R}$ using

$$
Z=a R^{b}
$$

Reflectivity $(\mathrm{Z})$ is proportional to the concentration of drops with fixed diameter D given in (1). The relationships proposed rain coefficients a and b vary, dependent on drop diameter and concentration, giving rise to unique relationships characteristic of different rainfall types. Measurements of polarization parameters, with increasing information on drop size, shape and orientation used for better estimates of rainfall rate (R) than those available from reflectivity alone.

The differential reflectivity $Z_{D R}$ and differential phase shift $\Phi_{D P}$ used for more accurate rainfall predictions [21]. It is proportional to the number of concentration of particles and tends to increase with increasing particle size and attractive variable to use for attenuation correction and quantitative precipitation estimation. Linear polarization techniques transmitting and receiving pulses with both vertical and horizontal returns $Z_{H}$ and $Z_{V}$ provide valuable measurements for estimate raindrop shape, size and orientation. We analyzed hourly, daily and weekly data based on observations are detected with a range of up to 250 or $450 \mathrm{~km}$ for constant altitude plan position indicator a horizontal cut through the atmosphere, plan position indicator volume scan at multiple elevation angles respectively.

The BAH weather radar since it is dual polarimetry collects horizontal and vertical reflectivity, Doppler velocity, and spectrum width data every 5 to 10 minutes (volume scan) for a three dimensional volume above the $\mathrm{C}$-band weather radar at the Bahir Dar location. By using meteorological algorithms used to track storm motion or to help access the severity of a particular storm cell in a particular location, vertically integrated liquid water and wind profile. This weather radar has high resolution which shows temporal and spatial variation of rain fall. When a new volume scan becomes available, the creation process stops where it is on the list and starts at the top of the list with the new data set. For typical dual polarization weather radar, the displayed variables are reflectivity, rainfall rate, radial velocity and spectrum width. The plan position indicator is a polar format display of a variable, obtained from a single full antenna rotation at one selected elevation. The range height indicator is display of a variable obtained from a single elevation sweep, typically from $0^{\circ}$ to $90^{\circ}$, at one azimuth. A horizontal cross-section display of a variable a specified altitude produced by interpolation from the volume data.

\section{RESUlts AND Discussions}

The Bahir Dar (BAH) weather radar which is dual polarimetry available to the meteorological research community in a number of forms from June, 2016 with both the vertical and horizontal pulses, this weather radar is better able to determine hydrometers type, shape, and size. It has important applications for operations to improve accuracy of precipitation estimation and the generation of hydrometer identification (HID) products. Meaningful information is obtained by comparing the amplitudes and phases of the signals returned at horizontal and vertical polarizations, providing a suite of new variables product values.

Reflectivity $(\mathrm{Z})$ is a measure of the radiation returned by atmospheric scattering to the radar. It is expressed in decibels of reflectivity (dBZ). The radial velocity measures the motion of the scattering medium along the beam, not the total motion of the medium and spectrum width (W) is a measure of dispersion of velocities. The Bahir Dar (BAH) C-band weather radar has different types of product outputs which have different purposes for estimation of rainfall, wind direction and forecast, Early warnings like thunderstorms, hail and flood.

BAH weather radar covers most west north and parts of central Ethiopia; the scan is used for producing basic products 
by using Scanning Strategies like the polar coordinate system common display of weather information. This weather radar is located at the center of the coordinate system and radar information from one antenna elevation scan is shown at the proper range and azimuth. With the conversion of these data to digital images, the ability to overlay a wide variety of information exists like political boundaries, cities and countries can be supplemented with highways or street locations, rivers and lakes.

The plan position indicator product can be configured to truncate the data at a range which is shorter than the actual task configuration range. It can improve a composite display by forcing the plan position indicator into a circle rather than a square. It can restrict the area of coverage for warn and track product. The RAIN1 product (Hourly Rain) uses CAPPI or SRI data over 60 minutes, to obtain an estimate of the rainfall that fell within an hour. The period of time desired for rainfall accumulation 60 minutes used to produce a one hour rainfall product however, the minimum accumulation time period allowed is 15 minutes. The RAINN is the sum any number of hours of individual RAIN1 products. The BAH weather radar product output shows the last $\mathrm{N}$ hours of accumulation. When the product runs, it integrates data for the last $\mathrm{N}$ hours. If a RAIN1 product is missing for one of the hours in the interval, it assumes that no rain fell during that hour. On July 01/2016 RainN for twenty four (24hr) UTC with range coverage $250 \mathrm{~km}$ volume-A scan as shown in Fig. 1 ; with resolution $809 \mathrm{~m} /$ pixel and its frequency is $600 \mathrm{~Hz}$ with maximum rain fall accumulation is $91.6 \mathrm{~mm}$.

The rainfall distribution over 24 hours is observed at Bahir Dar, parts of lake Tana, most northern parts and western parts of Gondar town; southern and western parts of lake Tana. RainN for twelve hour (12 hr) UTC the maximum rain fall distribution is $42.0 \mathrm{~mm}$ with an azimuth angle 16 degree; a range of 223 and an azimuth angle 258 with a range of $99 \mathrm{~km}$. For RainN 12hr UTC (Fig. 2) distribution rainfall have been made some correction in order to overcome topography of the surface southwest of the BAH weather radar and some parts of east from the position BAH weather radar. After correction with an azimuth angle of 268 degree and a range $96 \mathrm{~km}$ the rain fall accumulation is $43.3 \mathrm{~mm}$.

The BAH vertically integrated liquid product is very important to understand the depth of atmosphere and precipitation aloft and not reach to the ground surface if in case missed by altitude or plan position indicators. It is very powerful to estimate storm activities within altitude interval as well as the extreme of storm is found when the layer height above the freezing level. If the layer height extends from the surface up to $3 \mathrm{~km}$, then the vertically integrated liquid values serve as a forecasting guide as to how much precipitation is likely to fall during the next few minutes.

The vertically integrated liquid covers $250 \mathrm{~km}$ the maximum height is $20.0 \mathrm{~km}$ with a resolution of $809 \mathrm{~m} / \mathrm{pixel}$ and frequency of $600 \mathrm{~Hz}$. The maximum rainfall achieved 45.8 $\mathrm{mm}$ and much amount of rainfall is observed North west Gonder, Ashere, South west of Adet, and eastern parts of Bahir Dar. Maximum reflective display product shows the maximum echoes on each pixels between user selected heights. The

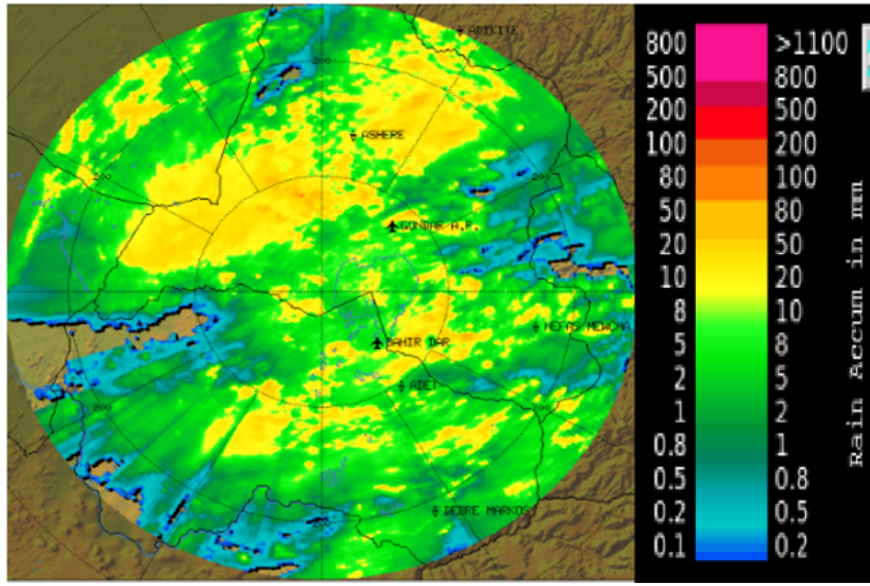

Fig. 2. RainN 24Hr UTC maximum rain fall accumulation of $91.6 \mathrm{~mm} 1$ July 2016

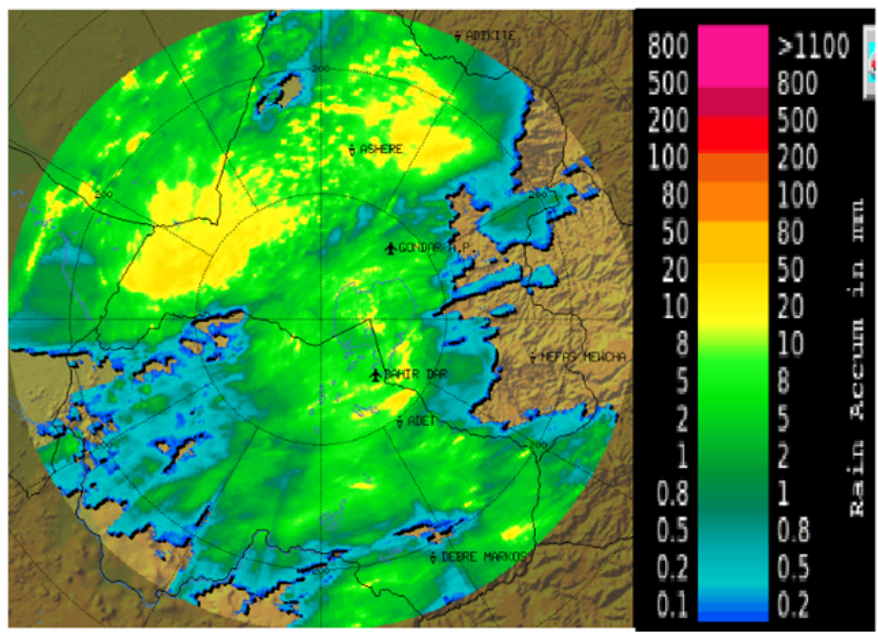

Fig. 3. RainN 12Hr UTC maximum rain fall accumulation of $43.3 \mathrm{~mm} 1 \mathrm{July}$ 2016

maximum height $15 \mathrm{~km}$ weather radar of first observation $250 \mathrm{~km}$ range with a resolution $882 \mathrm{~m} /$ pixel and frequency of $600 \mathrm{~Hz}$. The maximum reflectivity is $59.5 \mathrm{dBz}$ and the minimum reflectivity $-27.0 \mathrm{dBz}$ and an azimuth angle 358 degree with range of $37 \mathrm{~km}$ as shown in Fig. 4. Constant altitude plan position indicator product is a horizontal cut through the atmosphere, therefore, it requires a PPI volume scan at multiple elevation angles. The number of angles and their spacing depends on the range and height of the constant altitude plan position indicator. Using the constant altitude plan position indicator product with the vertical height of 1 $\mathrm{km}$ and range of $125 \mathrm{~km}$ using volume A scanning method from time 17:00:45 UTC to 17:55:45 UTC of 26 June 2016 are listed in the following table.

Table 1 shows resolution (m)/pixel of 347 and pulse repetition frequency (PRF) of $600 \mathrm{~Hz}$. From the above Table 1 the range of minimum reflectivity through a given time in between $-18.0-12.5 \mathrm{dBz}$ and the range of maximum reflectivity is 50 $53.5 \mathrm{dBz}$. The minimum reflectivity is observed at azimuth angle of 124 degree and a range of $33 \mathrm{~km}$ and the maximum reflectivity observed at azimuth angle 208 degree and a range 


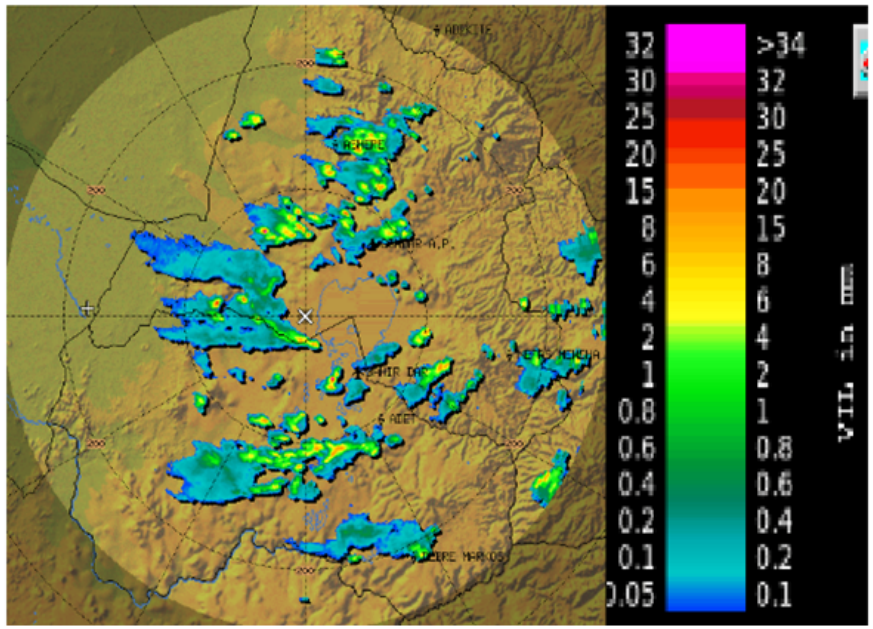

Fig. 4. Vertical integrated liquid (VIL) with maximum height $20 \mathrm{~km}$ maximum rain fall accumulation of 1 July 2016

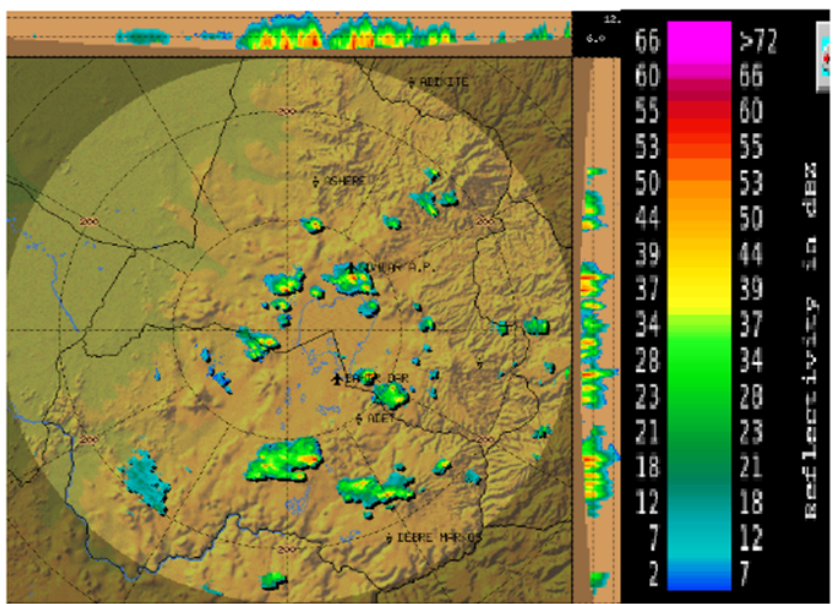

Fig. 5. Maximum reflective display with maximum height $15 \mathrm{~km}$ maximum rain fall accumulation of $59.5 \mathrm{~mm} 29$ June 2016

\section{of $79 \mathrm{~km}$.}

The amount of precipitation concentration is directly related to radar reflectivity. When amount of reflectivity is high the amount of hydrometer is high. From the reflectivity rain fall and warning issues are estimated. In 26 June 2016 for the last of 55 minutes we observed $53.5 \mathrm{dBz}$ maximum reflectivity south west region from the site of Bahir Dar weather radar. The BAH Echo Tops product is a display image of the height of the highest occurrence of a selectable threshold dBZ contour. A $50 \mathrm{dBZ}$ top $1 \mathrm{~km}$ above the freezing level produce a vigorous convective storm. Echo Tops over a range of $250 \mathrm{Km}$ with Vol-A scanning method and its resolution is $694 \mathrm{~m} /$ pixel with a pulse repetition frequency of $600 \mathrm{~Hz}$. The maximum height $18.9 \mathrm{~km}$ and $2.3 \mathrm{~km}$ is the minimum height.

The Base resolution is $809 \mathrm{~m} / \mathrm{pixel}$ and with pulse repetition frequency of $600 \mathrm{~Hz}$ depicted in Fig. 6. The maximum height that achieved by the base reflectivity is $14.4 \mathrm{~km}$ and minimum height is $2.3 \mathrm{~km}$ at 12:36:03 UTC in 29 June 2016.

The BAH weather radar has a capability for observing further vertical structure of a storm. Area of interest can be
TABLE I

THE CAPPI PRODUCT WITH THE VERTICAL HEIGHT OF $1 \mathrm{KM}$ WITH AZIMUTH RANGE OF MINIMUM AND MAXIMUM REFLECTIVITY USING VOLUME A SCANNING METHOD

\begin{tabular}{|c|c|c|c|c|c|c|}
\hline $\begin{array}{c}\text { Max } \\
\text { dBZ }\end{array}$ & $\begin{array}{c}\text { Azimuth } \\
\text { degree }\end{array}$ & $\begin{array}{c}\text { range } \\
\mathrm{km}\end{array}$ & $\begin{array}{c}\text { Min } \\
\mathrm{dBZ}\end{array}$ & $\begin{array}{c}\text { Azimuth } \\
\text { degree }\end{array}$ & $\begin{array}{c}\text { range } \\
\mathrm{km}\end{array}$ & $\begin{array}{c}\text { Time } \\
\text { UTC }\end{array}$ \\
\hline \hline 53.5 & 208 & 79 & -18 & 124 & 33 & $17: 00: 45$ \\
\hline 52.5 & 156 & 77 & -16 & 105 & 90 & $17: 05: 45$ \\
\hline 53 & 229 & 105 & -16 & 247 & 63 & $17: 10: 45$ \\
\hline 52 & 140 & 96 & -14.5 & 101 & 90 & $17: 15: 45$ \\
\hline 50 & 212 & 101 & -16 & 260 & 85 & $17: 20: 45$ \\
\hline 51 & 132 & 121 & -14.5 & 254 & 56 & $17: 25: 45$ \\
\hline 51 & 134 & 120 & -14.5 & 134 & 20 & $17: 30: 45$ \\
\hline 52 & 136 & 119 & -15 & 253 & 52 & $17: 35: 45$ \\
\hline 52 & 195 & 92 & -15.5 & 100 & 91 & $17: 40: 45$ \\
\hline 52 & 196 & 93 & -14.5 & 254 & 56 & $17: 45: 45$ \\
\hline 51.5 & 134 & 88 & -14.5 & 102 & 55 & $17: 50: 45$ \\
\hline 52 & 190 & 61 & -12.5 & 281 & 7 & $17: 55: 45$ \\
\hline
\end{tabular}

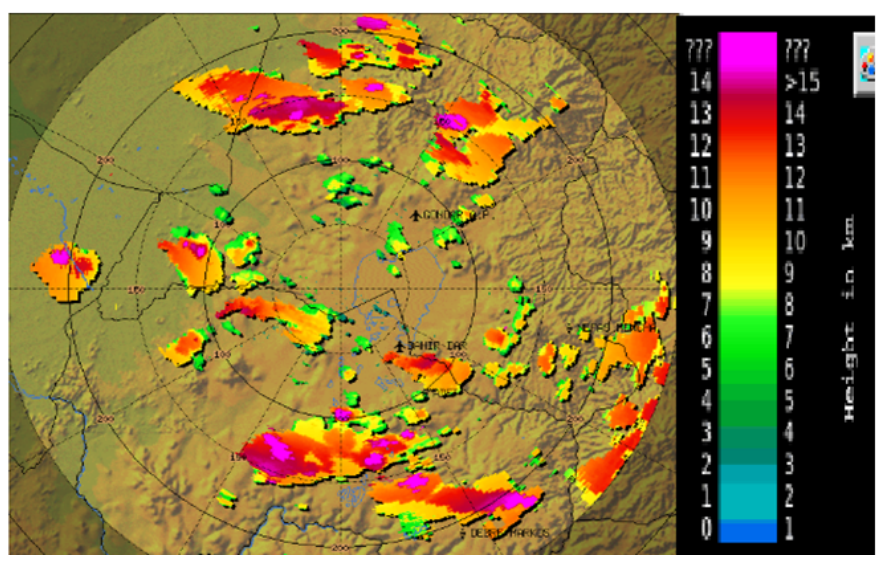

Fig. 6. TOPS with maximum height $18.9 \mathrm{~km}$ maximum and minimum $3.2 \mathrm{~km}$ 28 June 2016

scheduled by RHI TASK. During RHI scanning, the antenna azimuth is fixed and the elevation is swept, typically from near $0^{\circ}$ to $90^{\circ}$ to create a vertical cross-section effect.

A display is generated with the range on the $\mathrm{x}$-axis and the height of the cloud targets on the y-axis. A Cartesian grid is displayed as on overlay to facilitate reading height of clouds as depicted on Fig. 7.

After a series input products at different temporal and spatial resolution the track products can be projected to visualize the movement of storm characteristics as shown in Fig. 8. The track shows movement of one centroid over a specified time span, plus a forecast point indicating where the centroid will be given its current direction and speed. As new data comes in, the track product evaluates whether a new track point is an extension of a previous track, the start of a new track, or the end of a track. Track parameters, such as the maximum velocity and tolerance for new points, influence this determination. Horizontal wind vectors are displayed as wind speed and direction with either wind barbs or wind strings.

Suppose the freezing level is at $4 \mathrm{~km}$, and we run an echo TOPS product for the $45 \mathrm{dBZ}$ contour. The TOPS product shows $45 \mathrm{dBZ}$ tops at heights greater than $5.5 \mathrm{~km}$, there is a high probability of hail. However this is not the only issue to determine occurrence of hail checking the region of hail 


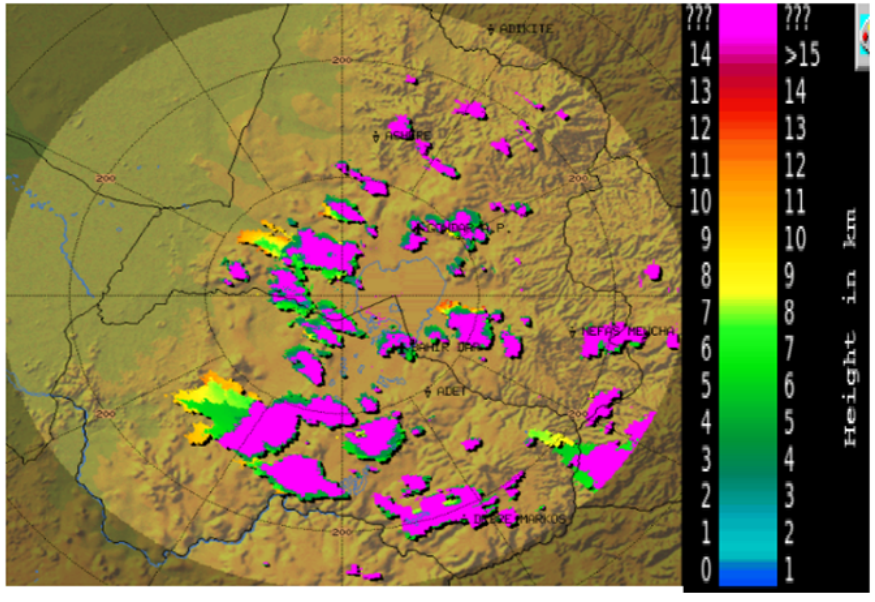

Fig. 7. base with maximum height $14.4 \mathrm{~km}$ maximum and minimum $2.3 \mathrm{~km}$ 29 June 2016

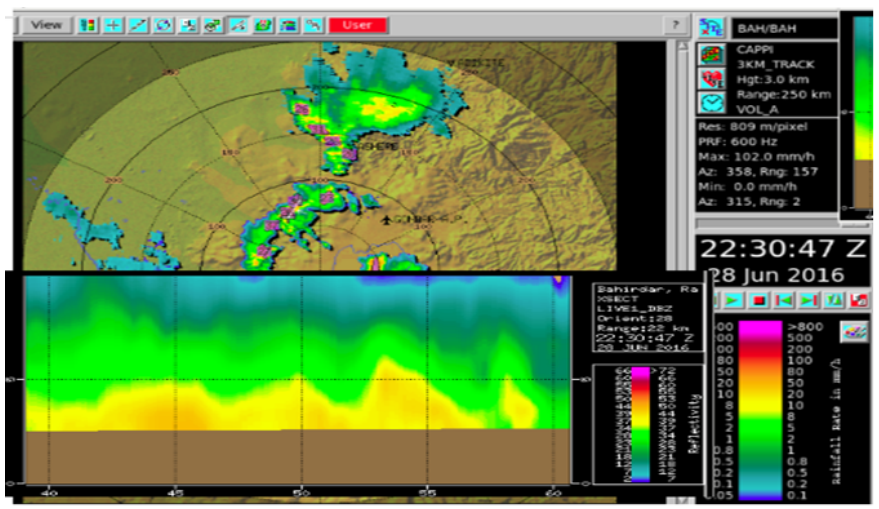

Fig. 8. RHI with maximum height $3 \mathrm{~km}$ maximum and rainfall accumulation $102.0 \mathrm{~mm} 28$ June 2016

signature is another mechanism to observe warning issues. The warnings are located mostly north east around $170 \mathrm{~km}$ from the weather radar at 18:00:44Z 27 June 2016 shown in Fig. 9.

\section{CONCLUSiOnS}

The Bahir Dar (BAH) weather radar operates in C-band of the electromagnetic spectrum with energy bands correspond to wavelength 4 to $8 \mathrm{~cm}$. It is a dual polarimetric radar available to the meteorological research community in a number of forms from June, 2016 onwards with both the vertical and horizontal pulses has potential to capture hydrometers' types, shapes, and sizes. Spatially and temporally covers North western parts and central parts of Ethiopia to observe and analyze different products. The Bahir dar weather radar for the first time observation has been detected with a range of up to $250 \mathrm{~km}$ or $450 \mathrm{~km}$ for constant altitude plan position indicator and plan position indicator respectively. The Bahir Dar C-band weather radar has different types of product output which have different purposes for estimation of rainfall, wind direction and forecast, warnings like thunderstorms, hail and flood. The vertical integrated layer product can compute several different values over an altitude interval or layer in the atmosphere. It can compute integrated liquid, or averaged reflectivity. The

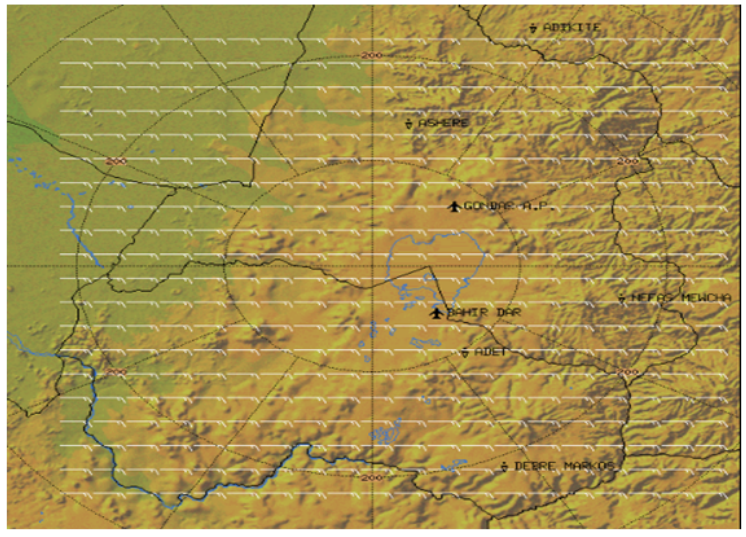

Fig. 9. 1km-TRACK volume scan method

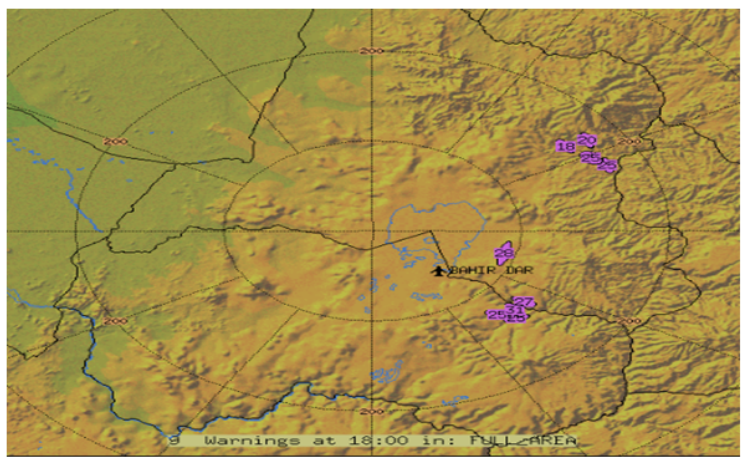

Fig. 10. Warning Constant Altitude Plan Position Indicator product of thunderstorm North East and South east from the weather radar station 27 June 2016

range of minimum reflectivity through a time of 17:00:45 UTC to $17: 55: 45$ UTC of 26 June 2016 in between $-18.0-12.5 \mathrm{dBz}$ and the range of maximum reflectivity is $50-53.5 \mathrm{dBz}$. The minimum reflectivity observed at azimuth angle 124 degree and a range of $33 \mathrm{~km}$ and the maximum reflectivity observed at azimuth angle 208 degree and a range of $79 \mathrm{~km}$.

\section{REFERENCES}

[1] T. Seliga and V. Bringi, "Potential use of radar differential reflectivity measurements at orthogonal polarizations for measuring precipitation," Journal of Applied Meteorology, vol. 15, no. 1, pp. 69-76, 1976.

[2] — "Differential reflectivity and differential phase shift: Applications in radar meteorology," Radio Science, vol. 13, no. 2, pp. 271-275, 1978.

[3] A. Jameson, "Microphysical interpretation of multi-parameter radar measurements in rain. part i: Interpretation of polarization measurements and estimation of raindrop shapes," Journal of the Atmospheric sciences, vol. 40, no. 7, pp. 1792-1802, 1983.

[4] A. Jameson and E. Mueller, "Estimation of propagation-differential phase shift from sequential orthogonal linear polarization radar measurements," Journal of Atmospheric and Oceanic Technology, vol. 2, no. 2, pp. 133-137, 1985.

[5] A. Jameson, "Microphysical interpretation of multiparameter radar measurements in rain. part iii: Interpretation and measurement of propagation differential phase shift between orthogonal linear polarizations," Journal of the Atmospheric Sciences, vol. 42, no. 6, pp. 607-614, 1985.

[6] M. Sachidananda and D. Zrnic, "Zdr measurement considerations for a fast scan capability radar," Radio Science, vol. 20, no. 4, pp. 907-922, 1985.

[7] - "Differential propagation phase shift and rainfall rate estimation," Radio Science, vol. 21, no. 2, pp. 235-247, 1986. 
[8] N. Balakrishnan and D. Zrnić, "Estimation of rain and hail rates in mixed-phase precipitation," Journal of the Atmospheric Sciences, vol. 47, no. 5, pp. 565-583, 1990.

[9] S. Giangrande and A. Ryzhkov, "Estimation of rainfall based on the results of polarimetric echo classification," Journal of applied meteorology and climatology, vol. 47, no. 9, pp. 2445-2462, 2008.

[10] N. Balakrishnan and D. Zrnic, "Use of polarization to characterize precipitation and discriminate large hail," Journal of the atmospheric sciences, vol. 47, no. 13, pp. 1525-1540, 1990.

[11] J. Picca and A. Ryzhkov, "A dual-wavelength polarimetric analysis of the 16 may 2010 oklahoma city extreme hailstorm," Monthly Weather Review, vol. 140, no. 4, pp. 1385-1403, 2012.

[12] M. Vojtesak, K. Martin, and G. Myles, "Swanea (southwest asianortheast africa): A climatological study. volume 1 . the horn of africa," AIR FORCE ENVIRONMENTAL TECHNICAL APPLICATIONS CENTER SCOTT AFB IL, Tech. Rep., 1990.

[13] L. Ayalew and H. Yamagishi, "Slope failures in the blue nile basin, as seen from landscape evolution perspective," Geomorphology, vol. 57, no. 1-2, pp. 95-116, 2004.

[14] S. Kebede, Y. Travi, T. Alemayehu, and T. Ayenew, "Groundwater recharge, circulation and geochemical evolution in the source region of the blue nile river, ethiopia," Applied Geochemistry, vol. 20, no. 9, pp. 1658-1676, 2005.

[15] S. Awulachew, M. McCartney, T. Steenhuis, and A. Ahmed, A review of hydrology, sediment and water resource use in the Blue Nile Basin. IWMI, 2009, vol. 131.

[16] A. Swain, "Challenges for water sharing in the nile basin: changing geopolitics and changing climate," Hydrological Sciences Journal, vol. 56, no. 4, pp. 687-702, 2011.

[17] M. Fazzini, C. Bisci, and P. Billi, "The climate of ethiopia," in Landscapes and landforms of Ethiopia. Springer, 2015, pp. 65-87.

[18] M. Gosset and I. Zawadzki, "Effect of nonuniform beam filling on the propagation of the radar signal at $\mathrm{x}$-band frequencies. part i: Changes in the k (z) relationship," Journal of Atmospheric and Oceanic Technology, vol. 18, no. 7, pp. 1113-1126, 2001.

[19] A. Illingworth, T. Blackman, and J. Goddard, "Improved rainfall estimates in convective storms using polarisation diversity radar," Hydrology and Earth System Sciences Discussions, vol. 4, no. 4, pp. 555-563, 2000.

[20] P. Austin, "Relation between measured radar reflectivity and surface rainfall," Monthly Weather Review, vol. 115, no. 5, pp. 1053-1070, 1987.

[21] C. Collier, "Developments in radar and remote-sensing methods for measuring and forecasting rainfall," Philosophical Transactions of the Royal Society of London. Series A: Mathematical, Physical and Engineering Sciences, vol. 360, no. 1796, pp. 1345-1361, 2002. 